\title{
Derechos Económicos, Sociales y Culturales: un caso de equilibrio precario entre la obligación constitucional, las restricciones presupuestarias y la desconfianza neoliberal
}

En el presente trabajo se pretende abordar el problema de la obligación del Estado de garantizar los derechos fundamentales contenidos en el artículo 19 de la Constitución, en particular los derechos económicos y sociales (en adelante también "Derechos Sociales"). En la primera sección se plantea una explicación al problema desde dos perspectivas, por un lado la económica, que da cuenta de la dificultad material para satisfacer dichos derechos, y por otro lado la jurídica, que discute si los derechos sociales son derechos y por ende pone en tela de juicio la exigibilidad de los mismos por parte de las personas. En la segunda sección se plantea que, dependiendo de la concepción de Estado y de democracia que se adopte dependerá el grado o medida en que se satisfarán los derechos sociales. En la tercera parte se argumenta que el programa Chile Solidario es un caso de programa público que abarca diversas áreas relacionadas con los derechos sociales desde una perspectiva de fortalecimiento de capacidades. Finalmente, en la cuarta parte se analiza, a modo de conclusión, las implicancias que tiene la concreción del programa Chile Solidario desde la perspectiva de los Títulos de intervención de la Administración..

* Abogado, Licenciado en

Ciencias Juridicas y Sociales. Ayudante adjunto Facultad de Derecho,

Universidad de Chile.

\section{Los Derechos Sociales al estrado: entre la obligación} constitucional, las restricciones presupuestarias y la desconfianza neoliberal

El problema de la satisfacción de los Derechos Sociales se presenta porque nuestra la Constitución chilena establece y garantiza un catálogo de derechos fundamentales bajo la siguiente fórmula jurídica, que encabeza el artículo 19 de la Constitución: 
"La Constitución asegura a todas las personas", para continuar con el desarrollo de 26 numerales entre los que se cuentan algunos que corresponden a la categoría de "Derechos Económicos Sociales y Culturales", que en adelante denominaremos Derechos Sociales ${ }^{1}$.

A partir de la opción normativa que adopta nuestra Constitución, el problema que surge radica en ¿Cómo el Estado, y en particular la Administración cumple con esta obligación de garantizar a todas las personas determinados Derechos Sociales?.

He omitido expresamente realizar cualquier intento de definición de los derechos sociales debido a que, precisamente, no existe un concepto unívoco que haga las veces de "cortafuegos" conceptual. Por lo mismo, para comprender este problema, en principio adoptaremos una definición operacional que los concibe como "derechos a prestaciones públicas positivas" 2 .

Para complementar esta definición, podemos señalar que estas prestaciones públicas positivas a que tienen derecho las personas en virtud de la obligación constitucional asumida por el Estado son, entre otras, el derecho a la salud, el derecho a la educación, el derecho a la seguridad social, el derecho a vivir en un medio ambiente libre de contaminación, entre otros. ${ }^{3}$

El problema surge cuando nos preguntamos si el Estado se encuentra efectivamente obligado a realizar aquellas cosas que promete en el texto constitucional, en función a que de los propios enunciados de estos derechos resulta muy difícil identificar las actividades necesarias de realizar, y por otra parte cualquier acción que se tome en dicho sentido implica consecuencias financieras para el Estado. En este punto nos encontramos con la paradoja de que estos derechos siempre transitan por un área conflictiva y, he aquí mi tesis central, que supone un precario equilibrio entre la obligación de responder a las expectativas ciudadanas por dichas prestaciones ${ }^{4}$ versus las demandas por responsabilidad fiscal, el control del gasto público y eficiencia del mercado. ${ }^{5}$

Esta posición polémica del rol del Estado frente a la satisfacción de las demandas so-

COURTIS, C. Los Derechos Sociales como Derechos. Trabajo presentado en SELA 2001.

FERRAJOLI, L. Derechos y Garantías. La ley del más débil Trotta,1999, p.108

Hacer cita a algún autor que de otros. Además, tradicionalmente se contemplan otras prestaciones que son incluidas en catálogos internacionales como son la habitación o vivienda digna, la alimentación, la cultura, el deporte, etc.

4 Al respecto Liliana López Lopera argumenta que la relación que existe entre el Estado y los particulares, en función de los derechos sociales es una basada en "titularidades" lo que implica que en virtud de ellas se produce [citando a Dahrendorf] "una relación entre las persona y los productos de consumo, mediante las cuales se "legitimiza" el acceso a y el control de ellos" continúa seńalando que "las titularidades conceden a las personas una pretensión legítima hacia las cosas, es decir, el derecho "para disponer de cosas a través de medios legales" LÓPEZ, L. La integralidad de los Derechos Humanos en ALONSO, M. y GIRALDO, J. (eds.) Ciudadanía y Derechos Humanos Sociales. Ediciones ENS, 2001, p.111.

5 Al respecto, Norbert L. ha desarrollado muy bien esta idea de precariedad del Estado respecto al rol que a este le compete en el mercado. Lechner reconoce que el Estado tiene un importante rol en el desarrollo económico y social de un país, pero que dicho rol es una suerte de "bisagra" del sistema, puesto que por una parte le corresponde asegurar el libre desenvolvimiento de los mercados, y por otra le corresponde hacer frente a las demandas por prestaciones sociales por parte de los ciudadanos. LECHNER, N. El debate sobre Estado y Mercado en Centro de Estudios Públicos Estudios Públicos No. 47, 1992, pp. 236-237. 
ciales se enfrenta, principalmente, a las críticas neoliberales que señalan que cualquier intervención del Estado en la economía es nefasta ${ }^{6}$, y que el descontrol del gasto fiscal es un anatema que no es posible soportar. Esta indefinición, propia del neoliberalismo, es la que provoca la paradoja que inspira esta sección, y no es otra que la tensión entre el desarrollo de los mercados, la apertura comercial internacional y la satisfacción de derechos sociales?

Hoy los gobiernos transitan por este equilibrio precario haciendo malabarismos para intentar satisfacer estas dos fuerzas poderosas y convergentes. Por de pronto la opción del equilibrio precario no es la única, pero es la más consistente y responde a una lógica constitucional concreta. ${ }^{8} \mathrm{El}$ modelo de desarrollo por el que la mayoría de los gobiernos en la región han adoptado, tiene en su "ADN" el sino de transitar por este equilibrio precario entre el crecimiento económico y la superación de la pobreza, esto se traduce en que "Cuando existe ya no sólo escasez sino miseria, las leyes del mercado resultan inoperantes (...) la propia dinámica del mercado exige correctivos externos para evitar que la inequidad se petrifique y tenga efectos intergeneracionales" ${ }^{\prime}$. Es decir, el Estado no se puede quedar de brazos cruzados.

\subsection{Los Derechos Sociales como correctivos externos a las inequidades del mercado.}

En su origen, la literatura está de acuerdo en que los derechos fundamentales nacen como una respuesta de clase de la burguesía hacia el poder de los estados absolutistas en pos de la garantía de determinados derechos que estos concebían como naturales (por ejemplo la propiedad) ${ }^{10}$.

Este primer momento fue el antecedente (y se transformó en la justificación) para el desarrollo de la sociedad liberal y -asociado a ella- una economía de mercado capi-

6 LECHNER, N. Op. cit. p. 238, señala Lechner: "La crisis del Estado desencadena la crítica al Estado. El neoliberalismo denuncia no solo el estatismo, sino que condena toda intervención estatal como consustancialmente nefasta”.

7 "Los países Latinoamericanos se enfrentan al siguiente dilema: por una parte su desarrollo socioeconómico depende de una inserción competitiva en los campos más dinámicos del mercado mundial.(...) Por otra parte, la apertura al exterior profundiza aún más las ya graves desigualdades sociales al interior de la sociedad latinoamericana. (...) Un tercio de la población latinoamericana está excluido del desarrollo y relegado a situación de pobreza" LECHNER, N. Op. cit. p. 240.

8 Existe la opción total por las garantías sociales por medio de estados que se cierran a la globalización económica y deciden ser "Estados Sociales" o bien abandonan al mercado la satisfacción de estas necesidades, como sucedió el caso de la Dictadura Militar chilena. Este caso lo resume Lechner seńalando que si bien es cierto que el mercado establecido opera como un elemento de integración sistémica; en el corto plazo el desarrollo de una economía de mercado incrementa las desigualdades sociales. En Chile, la dictadura avanzó decididamente en una estrategia neoliberal. Entre 1978 y 1988 el 20\% más rico de los hogares de Santiago aumentó su participación en el consumo total de 51 a $55 \%$, en tanto que todos los demás sectores vieron disminuida su proporción” LECHNER, N. Op. cit. p. 243.

9 Ibid.

10 CRISTI, R. y RUIZ-TAGLE, P. ¿Qué es el Constitucionalismo? en RUIZ-TAGLE, P. Y CRISTI, R. La República en Chile. Teoría y práctica del constitucionalismo republicano Lom, 2006, pp. 29-43. 
talista, en la cual la base para generar riqueza fue el esfuerzo individual. No obstante el impulso modernizador inherente a este modelo, una de sus consecuencias más nefastas es el surgimiento de grandes inequidades sociales que amenazan las bases mismas del sistema.

El desafío, en términos de superación de las desigualdades, que impone este modelo es grande, y radica en ubicar el rol que le compete al Estado ${ }^{11} \mathrm{y}$ al constitucionalismo ante esta realidad, en un escenario de creciente globalización e influencia del poder de las empresas transnacionales, y de adecuación (uniformación) mundial de estructuras políticas y jurídicas, los derechos fundamentales, en este caso los sociales, asoman -nuevamente- como el bastión que sostiene la esperanza de millones de seres humanos que se encuentran excluidos actualmente de los bienes y la riqueza generada por el modelo. $^{12}$

De esta forma, los derechos sociales se han transformado en verdaderos escudos protectores, no del ciudadano en contra del Estado, sino de los ciudadanos (e incluso el Estado) en contra de los poderes económicos que obstaculizan las pretensiones de igualdad e inclusión, que se materializan en los agentes del neoliberalismo, las transnacionales y las grandes empresas ${ }^{13}$.

En este contexto, la polémica en torno a la exigibilidad del cumplimiento al Estado de las obligaciones que emanan los derechos que concede, aparece como una discusión académica y ajena a la realidad que exige y reclama acciones concretas para los sectores excluidos de la población, al respecto se ha seńalado "Sólo ahora, con los peligros del desmonte del Estado de bienestar, cobran significado los derechos sociales fundamentales por vía de la aplicación del principio de igualdad de trato y de oportunidades. De cualquier forma, un derecho al mínimo existencial, el cual incluye los derechos sociales fundamentales mínimos, parece un límite constitucional infranqueable en el desmonte de los servicios públicos estatales." ${ }^{14}$

Existen hipótesis en las cuales, la inactividad del Estado ${ }^{15}$ significa un grave perjuicio

11 En este sentido "El Estado encuentra crecientes dificultades no sólo para abordar la complejidad de la globalización, sino que igualmente para asumir una de sus funciones primordiales: la cohesión social. Por un lado, entró en crisis el instrumento keynesiano del Welfare State para compensar las disfuncionalidades del mercado. Por otro, el Estado no puede retirarse al rol subsidiario que le asignan los neoliberales. LECHNER, N. Op. cit. p. 243.

12 El constitucionalismo es el movimiento político e intelectual que tiene como propósito la sujeción del poder político al derecho, en función de ello, señalan Cristi y Ruiz-Tagle que: "El gobierno debe no solo evitar interferir en los derechos fundamentales, sino que también es responsable de promoverlos (...) Toda institución pública y privada debe someterse al imperio de los derechos fundamentales, incluyendo las ramas del gobierno ejecutiva, legislativa y judicial" Op. cit. p. 41.

13 "Hoy en día las opiniones convergen en torno a la necesidad de una intervención del Estado para contrarrestar la tendencia estructural a la desintegración social" LECHNER, N. Op. cit. p. 24.

14 ARANGO, R Protección Nacional e Internacional de los Derechos Humanos sociales en ALONSO, M. y GIRALDO, Op. cit. p. 161.

$15 \mathrm{Al}$ respecto se ha señalado que la inactividad del Estado en esta área se trata “(...) una inactividad protuberante del Estado en terrenos cuya acción es objetivamente necesaria para la realización de un derecho fundamental. Piénsese en los servicios básicos de salud y de educación: su deficiente prestación conduce a la violación de los derechos fundamentales de amplios sectores pobres que por su cuenta no pueden contratar privadamente estos servicios. Ibid. 
contra sus ciudadanos, sobre todo en las áreas propias de cobertura de los derechos sociales, tales como educación, salud, vivienda, alimentación, etc., que ponen en entredicho la definición de dignidad, propia del constitucionalismo. En tales hipótesis de urgencia, no es posible sostener, a juicio de consideraciones teóricas y/o "sistémicas" que el Estado tiene que abstenerse de actuar en beneficio de otros valores, como el rígido principio de la separación de poderes o la vilipendiada "legitimidad democrática". En este escenario de urgencia, a la Administración, le corresponde un papel clave en la satisfacción de estos derechos.

La pregunta es, ¿En caso de graves violaciones a los derechos sociales, nos quedamos de brazos cruzados esperando por la resolución dogmática de a quién le compete la satisfacción de estas necesidades? Mi respuesta es no, y es categórica, y es tan categórica no "a pesar del equilibrio precario" que he sostenido como característica de la satisfacción de los derechos sociales, sino gracias a dicha precariedad. En un mundo en el que los desequilibrios y asimetrías son la constante, en el cual el poder y la riqueza están tan igualmente distribuidos, la esperanza de millones descansa en un precario equilibrio, que sostiene se fundamenta en la dignidad de la persona.

Uno de los fundamentos de la esperanza en el equilibrio precario descansa en lo que, a juicio de ARANGO, es la llave de la solución a la legitimidad de la actuación del Estado en el área de los derechos sociales ${ }^{16}$ la tesis de la "urgencia" que se explica de la siguiente forma: "La urgencia de la situación concreta para el individuo, esto es, la alta probabilidad de la afectación indirecta de otros derechos fundamentales (teoría de la conexidad) justifica la aplicación de un control de resultado aplicable a la actuación omisiva del Estado por vía de una demanda de protección de los derechos fundamentales" 17

En definitiva, la tesis de la urgencia nos lleva a redefinir la relación que existe entre Estado, mercado y democracia, en resumidas cuentas, puesto que estos tres elementos convergen en un punto que es central para mi argumento, la dignidad de la persona exige que el Estado provea soluciones públicas que sean coherentes, coordinadas y

16 Arango argumenta en esta sección a favor del control constitucional "ilustrado" en materia de implementación de los derechos sociales. Yo utilizo su tesis para afirmar la actuación no solo de los jueces en el control de dichos derechos, sino que también el Legislador, y en lo que nos interesa en este trabajo, la Administración.

17 ARANGO, R. Op. cit. p. 162. Aparte de lo señalado por Arango, En este punto, apelando a la tesis del equilibrio precario, tengo un voto de deferencia para el Estado (y en particular a la administración y el legislador) por las omisiones en las que se ven obligados muchas veces a hacer, a causa de las presiones de grupos de poder tanto nacionales como internacionales, como es el caso del Banco Mundial, que a menudo se traducen en verdaderas imposiciones respecto al diseńo de políticas a favor del status quo que alimenta al Neoliberalismo. Respecto a este punto, Lechner señala: "Actualmente las instancias internacionales (Banco Mundial, IMF, etc.) restringen la autonomía estatal de modo que numerosos instrumentos (política monetaria, gasto fiscal) que antes estaban a disposición del Estado, ahora se han transformado en condiciones o parámetros externos que fijan el marco de acción estatal" LECHNER, N. Op. cit. p. 243. 
fundadas en estos tres elementos ${ }^{1819}$.

Volviendo sobre el concepto de derechos sociales, pese a la contundencia de los argumentos a favor de considerarlos como piezas claves para el desarrollo de la persona y como correctivos indispensables a las inequidades del mercado, su consagración aún es resistida por diversos sectores, y un consenso respecto a la conveniencia de establecerlos en las constituciones encuentra aún muchos detractores. A continuación se presentan algunas de las principales objeciones en contra de los derechos sociales, sin un ánimo de explorar en profundidad dicha discusión, que es frondosa en la literatura constitucional, sino que con el propósito de reafirmar la tesis del equilibrio precario y la urgencia que justifican su inclusión normativa y que obligan al Estado a tomar decisiones concretas en su favor.

\subsection{La desconfianza neoliberal: ¿Existen los derechos sociales?}

El neoliberalismo, como ideología política, jurídica y económica concibe la relación que anteriormente identificamos entre Estado, Mercado y Democracia totalmente subordinada a uno de sus elementos, el Mercado, relación en la cual, la importancia

18 Esta solución coordinada se presenta en los siguientes términos, la democracia se funda en sujetos de derechos que por medio de deliberación política brindan legitimidad al Estado, que por su parte está obligado a garantizar los derechos de que disponen sus ciudadanos en cuanto tales (no en cuanto otras categorías diversas) y a su vez, el mercado es el espacio donde los ciudadanos y el Estado conversan libremente, realizan transacciones y es el espacio garantizado para el desarrollo de la libre iniciativa privada en materia económica, pero dicha libre iniciativa no puede volcarse en contra de los ciudadanos bajo la forma de desigualdad y exclusión. Cierra este círculo virtuoso un Estado lo suficientemente fuerte y legítimo como para garantizar a lo menos dos cosas: el respeto por el derecho y la corrección de las inequidades que se generen en el mercado. En definitiva, el argumento es que hoy, la actuación del Estado se resume en la máxima "No solo de mercado vive la democracia"

19 En un interesante trabajo, Mauricio García Villegas analiza el fenómeno de la relación entre el mercado, la democracia y el cumplimiento del derecho. El argumento de García radica en que la adopción de modelos como el neoliberal, ha generado que el derecho se transforme en un conjunto vacío, de bajos grados de cumplimiento por parte, principalmente por parte de aquellos agentes que gozan de posiciones de poder preferenciadas en la sociedad. A modo de diagnóstico de esta situación seńala: "La idea de una ciudadanía universal fundada en los derechos humanos promovida por las revoluciones de comienzos del siglo XIX nunca logró consolidarse plenamente en América Latina. (...) El Estado adolecía de grandes deficiencias en su función de hacer cumplir el derecho, lo cual convertía a los postulados universalistas de igualdad y derecho en retórica más que realidad." García argumenta que la clave para evitar este fenómeno radica en la fortaleza, tanto del Estado como de sus instituciones señalando, a propósito del neoinstitucionalismo "La falta de normas formales en las sociedades primitivas era compensada por una densa red de estructuras informales de tipo moral u religioso que creaba lazos estrechos entre las personas, de modo que las conductas desviadas eran consideradas como atentados contra la sociedad. A medida que las relaciones sociales y la sociedad entera se tornan más complejas, se hace apremiante la necesidad de instituciones que reduzcan la complejidad de las transacciones. En estas condiciones de complejidad creciente, los costos de información, la falta de un gobierno eficaz, la insuficiente tecnología, la escasez de bienes y de oficios pueden dar lugar a un "gobierno débil, a la adscripción de derechos y obligaciones con base en la pertenencia a una familia [citando a R. Posner] (...) Algunas sociedades lograron limitar la incertidumbre con la introducción de normas formales, mediante un proceso político eficiente, que garantizaron el cumplimiento de los contratos e hicieron más predecibles los intercambios. Los que no lograron encontrar la fórmula institucional para avanzar hacia la modernidad quedaron atrapadas en el subdesarrollo: un mundo en el que no se maximiza la riqueza (...)" GARCÍA, M. No sólo de Mercado vive la Democracia. El fenómeno del (in)cumplimiento del derecho y su relación con el desarrollo, la justicia y la democracia en Revista de Economía Institucional Vol. 6, $\mathrm{N}^{\circ} 10$, Primer Semestre, 2004, pp. 96; 110-111. 
del Estado y la Democracia es residual frente al discurso autómata de proteger su eficiencia y justicia.

La justificación de este sometimiento (o deferencia total al mercado) parte de la base de que dicho modelo supone que las personas son individuos orientados racionalmente hacia la consecución de sus intereses básicos, definidos (y concebidos) como derechos naturales, a la vida, la libertad y la propiedad, ${ }^{20}$ que son anteriores al Estado y a la democracia (y por ende al Derecho).

Es en función de la protección de estos derechos naturales que los individuos deciden renunciar a porciones de libertad con el propósito de construir instituciones públicas que permitan el adecuado resguardo de dichos derechos. De esta forma, el rol que le compete al Estado es residual. ${ }^{21}$ Es más, para un Neoliberal, el Estado es una suerte de conjunto vacío, cuyo posible contenido es precisamente su gran límite: la defensa de la autonomía privada. En este sentido, cualquier intervención del Estado que supere e incida en la autonomía privada y su derecho privilegiado, la propiedad, no es tolerable en este esquema, por ende, cualquier intento redistributivo de la riqueza y los bienes en la sociedad es visto como un atentado a la propiedad. Se concibe al Estado como un ente separado de la sociedad ${ }^{22}$, y es la sociedad, por medio de la libre iniciativa privada que se desarrolla en el mercado, la encargada de satisfacer las necesidades sociales. ${ }^{23}$

La desconfianza hacia los derechos sociales no es solo atribuible al neoliberalismo. En nuestra dogmática Fernando Atria ha sido un férreo opositor a la idea que se establezcan derechos sociales (y fundamentales) en las constituciones; así como también duda de la eficacia de las constituciones, en sí, como medio de control del poder político. La crítica de Atria, es sin duda una de las más complejas en la materia precisamente porque critica el establecimiento de derechos sociales desde perspectivas explícitas, como la socialista y desde perspectivas implícitas e incompatibles a esta última, como la neoliberal y la autoritaria propia de Carl Shmitt ${ }^{24}$.

20 CORTÉS, F. El proyecto político democrático y la cuestión de los derechos humanos sociales en ALONSO, M. y GIRALDO, J. Op. cit. p. 66.

${ }^{21}$ Este rol sería el de "(...) crear las condiciones para que los individuos puedan ejercer su libertad, es decir, su autonomía privada. El ámbito de su libertad comprende aquel espacio de juego que se extiende hasta los límites del espacio de acción necesario para el ejercicio de la libertad del otro, y la tarea del Estado liberal es trazar claramente esas fronteras y hacerlas valer contra las interferencias provenientes de las mismas autoridades del Estado, o de cualquiera de sus individuos”. CORTÉS, F. Op. cit, p. 69.

22 Al respecto Cortés señala "Complementariamente, la política se define en función de los intereses de la persona de derecho privado. La estructura y el funcionamiento de las instituciones democráticas está delimitada por el espacio en el que son coordinados y negociados los intereses de individuos y grupos que, organizados como partidos políticos, gremios, sindicatos y grupos de presión, realizan su mandato siguiendo los procedimientos formales constituidos para el ejercicio de la actividad política en las democracias modernas. Finalmente, la participación ciudadana se entiende como la intervención ocasional, a través del voto, en los procesos de representación política, y se define en función de la búsqueda e condiciones favorables para la consecución de los intereses individuales. Al ciudadano, como portador de los derechos subjetivos de acción, le interesa que el Estado garantice el ejercicio de las libertades individuales" CORTÉS, F. Op. cit, p. 68.

23 "(...) cualquier tipo de intromisión del Estado en el ámbito individual, justificada por motivos de eficiencia, de equidad o de justicia social, es inaceptable."CORTÉS, F. Op. cit, p. 69.

24 Al respecto Ruiz-Tagle seńala: "Atria toma en cuenta particularmente la Teoría de la Constitución (Schmitt, 1934) y El concepto de lo politico (Schmitt, 1991) y hace suyo el principio de distribución de los derechos fundamentales 
Sin hacer un análisis en profundidad respecto de las objeciones a establecer derechos sociales en la constitución y su correlativa exigibilidad expondré algunos de los argumentos de Atria con el propósito de reforzar la tesis de este trabajo, en términos de resaltar el rol del Estado (y por ende de la Administración) respecto a la garantía de los derechos sociales.

En primer lugar, Atria desconfía del derecho y de los derechos fundamentales, puesto que estos serían controles ilegítimos a la actividad política ${ }^{25}$ y su establecimiento en constituciones "petrifica" el debate político. ${ }^{26}$ Por otra parte, señala que en particular, la utilización de la categoría de "derechos sociales" implica una contradicción en si misma, puesto que el fin que éstos buscan, resguardar condiciones sociales igualitarias para los ciudadanos, que sería fin propio de visiones socialistas es incompatible con el lenguaje de los derechos, que es de naturaleza eminentemente liberal e individualista. ${ }^{27}$ De acuerdo a estas consideraciones, para Atria (aunque no lo señala expresamente en el texto) la garantía de los derechos sociales debe quedar entregada al debate político ${ }^{28}$.

Por su parte, Roberto Gargarella, desde una perspectiva socialista, señala que el incluir derechos sociales en la constitución da cuenta de la debilidad del Estado de garantizarlos adecuadamente y representan la mayor derrota del socialismo. ${ }^{29}$ En resumidas cuentas, el reclamo de Gargarella apunta a que mediante el lenguaje liberal (e individual) de

en términos iusfundamentalistas semejantes a Shmitt. (...) Este principio determina que la libertad de los individuos es anterior al Estado y es, en principio ilimitada; y que la facultad del Estado para interferir en esa esfera de libertad es, y debe ser, en principio, limitada (Atria, 2003) RUIZ-TAGLE, P. La influencia de Carl Shmitt en Chile en RUIZ-TAGLE, P. Y CRISTI, R. Op. cit. p. 156.

25 Atria señala: "Hoy, sin embargo, la relación entre derecho y política se ha invertido y se nos invita a celebrar la sujeción de la política al derecho” ATRIA, F. ¿Existen los Derechos Sociales? en MICHELON, C. (ed.) Discusiones: Derechos Sociales Año IV No. 4, Editorial Universitaria de la Universidad Nacional del Sur, 2005, p. 36.

26 Para una discusión en relación con las objeciones a la legitimidad de los derechos fundamentales incluídos en cláusulas constitucionales ver: MORESO, J.J. Derechos y Justicia Procesal Imperfecta, GARGARELLA, R. Los Jueces frente al coto vedado y BAYÓN, J. C. Derechos, Democracia y Constitución en Discusiones, $\mathrm{N}^{\circ} 1,(2001)$ Para resumir esta discusión, Moreso defiende la idea que es necesario establecer derechos fundamentales en las constituciones porque su establecimiento es una garantía para las minorías frente a las decisiones de la mayoría, además defiende el principio de revisión judicial de los mismos porque a los jueces, por razones de eficacia y separación de poderes corresponde la resolución de controversias de carácter jurídico en una sociedad, finalmente defiende la tesis de que los derechos fundamentales en la constitución es una suerte de "seguro" social en caso que las mayorías, en el futuro desconozcan los derechos que han establecido en constituciones. Por su parte, en contrario, tanto Bayón como Gargarella argumentan en contra de esta posición señalando que el establecer derechos en las constituciones constituye un "coto vedado" que excluye del debate democrático determinados temas que aparecen blindados por un poder de veto que se le concede a las minorías, por otro lado, seńalan que los jueces no pueden resolver problemas que son de índole política y que la resolución de conflictos de derechos debe ser resuelta por la libre deliberación democrática.

27 ATRIA, F. Op. cit. pp. 15-38.

28 Atria da cuenta de la posición de Carlos Rosenkrantz, que señala que los derechos sociales ni siquiera deberían establecerse, puesto que supondrían una promesa, por parte del Estado, que no es posible ni seguro que sea cumplida. El sentimiento de frustración frente a dicho incumplimiento generaría un efecto perverso de deslegitimación de la Constitución y del Estado. ATRIA, F. Op. cit. pp. 46-48.

29 Señala Gargarella "Según entiendo, la recepción constitucional de los derechos sociales no evidencia una victoria clamorosa del socialismo [replica a Norberto Bobbio, quién sostiene que el establecimiento de estos derechos en la constitución es un triunfo del socialismo] sino que expresa las dimensiones de su lamentable derrota. GARGARELLA, R. Derecho y disociación. Un comentario a "Existen los derechos sociales" de Fernando Atria. en MICHELON, C. Op. cit. p. 63. 
los derechos no se pueden satisfacer las exigencias igualitarias y redistributivas que suponen los derechos sociales, quedando las declaraciones que los contienen como normas programáticas que no pueden ser exigibles judicial o administrativamente al Estado, que es la característica saliente de los derechos fundamentales como derechos subjetivos.

Como podemos apreciar, la respuesta que se den a las objeciones planteadas por el Neoliberalismo, y las posturas de Atria y Gargarella confluyen en torno al objeto central de este trabajo, que el Estado tiene la obligación de adoptar todas las medidas que estén a su alcance para garantizar los derechos sociales.

\section{Del Estado de Derecho al Estado Social, Democrático y Constitucional de Derecho: los derechos sociales como títulos de intervención de la Administración}

Los derechos sociales son tan derechos fundamentales como los tradicionales derechos civiles y políticos, herederos del liberalismo clásico, ya que comparten con éstos una serie de características que los homologan, tanto a nivel de su exigibilidad como a nivel de las obligaciones que imponen a los Estados. En este sentido, Víctor Abramovich y Cristian Courtis han construido sólidos argumentos para sostener este principio ${ }^{30}$.

Para efectos de este trabajo, señalaré que estoy de acuerdo con Courtis cuando señala que, mediante la adopción de constituciones y tratados internacionales el Estado se obliga a la satisfacción de estos derechos ${ }^{31}$. Es más, adicionalmente a este argumento de derecho positivo, que de por sí es concluyente, Courtis asegura que, tradicionalmente se ha señalado que la principal razón para diferenciar entre los derechos civiles y políticos y los derechos sociales, es que los primeros generan obligaciones de no hacer para el estado, es decir, obligaciones de abstenerse de causar daños, y por ende dicha acción no importa una afectación fiscal mayor, mientras que los derechos sociales generan para el Estado una obligación de hacer, es decir, brindar prestaciones materiales para su satisfacción, lo que además de la indeterminación propia de dicha concepción, genera un alto impacto fiscal, razón por la cual, en caso que las personas pudieran exigir estos derechos, finalmente serían los jueces los que acabarían determinando las

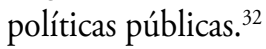

Agrega Courtis que los derechos civiles y políticos, sin embargo también importan

30 Ver ABRAMOVICH, V. Una aproximación al enfoque de derechos en las estrategias y politicas de desarrollo en Revista de la CEPAL 88. Abril 2006; COURTIS, C. Politicas sociales, programas sociales, derechos sociales. Ideas para una construcción garantista en Conference Paper PNUD México. 2007; COURTIS, C. Los derechos sociales como derechos conferencia presentada en SELA 2001; ABRAMOVICH, V y COURTIS, C. Los derechos sociales como derechos exigibles Trotta, 2006.

31 COURTIS, C. (2001) Op. cit., p. 1.

32 COURTIS, C. (2001) Op. cit. p. 2-6. 
obligaciones de hacer para el Estado ${ }^{33}$, principalmente relacionadas con el establecimiento de sistemas destinados a la protección de la propiedad y las libertades públicas, por lo mismo, señala que la mentada diferencia entre los derechos civiles y políticos y los sociales es solo de grado y no de naturaleza, por lo que si no considerábamos obligado al Estado respecto de los derechos sociales, de la misma manera que sí lo estaba respecto de los civiles y políticos, a causa de que estos no imponían obligaciones de hacer al Estado, dicha diferencia es infundada, debido a que los derechos sociales comparten las mismas características de los derechos civiles y políticos de implicar un complejo de actividades de hacer y no hacer, señala Courtis "Puede reconocerse que la faceta más visible de los derechos económicos, sociales y culturales son las obligaciones de hacer, y es por ello que a veces se los denomina "derechos-prestación". Sin embargo, no resulta difícil descubrir cuando se observa la estructura de estos derechos la existencia concomitante de obligaciones de no hacer: el derecho a la salud conlleva la obligación estatal de no dañar la salud; el derecho a la educación supone la obligación de no empeorar la educación; el derecho a la preservación de un medio ambiente sano implica la obligación de no destruir el medio ambiente. (...) muchas de las acciones legales tendentes a la aplicación judicial de los derechos económicos, sociales y culturales se dirigen a corregir la actividad estatal cuando ésta incumple con obligaciones de no hacer. En suma, los derechos económicos, sociales y culturales también pueden ser caracterizados como un complejo de obligaciones positivas y negativas por parte del Estado, aunque en este caso las obligaciones positivas revistan una importancia simbólica mayor para identificarlos." ${ }^{34}$

De esta forma, podemos afirmar que los derechos sociales imponen al Estado obligaciones jurídicas concretas para desarrollar actividades o no realizarlas con el propósito de resguardarlos. En este trabajo veremos cuáles son los títulos de intervención en virtud de los cuales el Estado actúa, y en particular veremos los títulos en virtud de los cuales la administración actúa para satisfacer estos derechos.

Una vez que hemos despejado la variable de porqué el Estado se encuentra efectivamente obligado a realizar acciones tendientes a lograr la satisfacción de los derechos sociales, debemos analizar el problema de cómo el Estado cumple con dicha labor, lo que nos lleva proponer una discusión previa breve, pero necesaria. Hay dos posiciones que debemos resolver previamente para resolver esta pregunta, en primer lugar cual es la concepción de Estado que valida la intervención en esta materia y cual es nuestra concepción de democracia que a su vez permite dicha legitimación. En primer lugar, debemos señalar que adoptaremos una visión sustantiva de la democracia, específicamente aquella desarrollada por Macpherson y que podríamos denominar como

33 A esta idea agrega López que “(...) los derechos sociales y económicos convierten al Estado en una instancia positiva encargada de satisfacer las demandas de bienestar y dignidad humana, es decir, este tipo de derechos se estructuran bajo la forma de expectativas positivas e imponen deberes de hacer, obligaciones al poder político" LOPEZ, L. Op. cit. p. 108.

34 COURTIS, C. (2001) Op. cit. p. 7. 
sustantiva, puesto que atiende no solo al aspecto procedimental de la democracia como mecanismo de elección de autoridades, sino que también apela al contenido que debiera tener la democracia como forma de gobierno, señala “¿Qué es esencial en la teoría moderna de la democracia? En la medida que la democracia es vista como una forma de ordenación social, y no meramente como un mecanismo de elección y autorización de las Autoridades, el principio igualitario inherente a la democracia requiere no solo "un hombre, un voto" sino que también "un hombre, un igualitario y efectivo derecho a vivir tan humanamente como se desee". La Democracia es ahora vista por aquéllos que la quieren y por aquéllos que la tienen (o han dicho que la tienen) y quieren más de ella, como un tipo de sociedad -un todo complejo de relaciones [entre individuos] - más que simplemente un sistema de gobierno" 35

Es decir, la democracia es un sistema de elecciones racionales, pero además es un sistema en el cual todos los ciudadanos que nos sometemos consideramos valioso que se nos reconozca el derecho de acceder a un nivel de vida adecuado. Bajo la forma de la denominada Democracia como desarrollo, que tiene sus orígenes en los escritos de John Stuart Mill encontramos la necesidad de contar con una estructura institucional que no solo resguarde la libertad y elección racional de las personas, sino que tenga como fin el máximo desarrollo material y espiritual posible, que se traduce en el derecho al desarrollo de la libre personalidad, este es el denominado modelo de la democracia como participación, desarrollado por Macpherson, modelo que responde a la tradición de la Democracia liberal, porque está basado en el principio ético democráticoliberal de la igualdad del derecho de todos los hombres y mujeres al pleno desarrollo y uso de sus capacidades. La Democracia como Participación requiere y exige, en lo que nos interesa "(...) que se rebajen o abandonen los supuestos de mercado acerca del carácter del hombre y la sociedad, que se abandone la imagen del hombre como consumidor maximizador y que se reduzcan mucho las desigualdades económicas y sociales actuales (...)"36

Así como necesitamos una teoría de la democracia que permita la posibilidad de exigir, institucionalmente, la garantía de poder gozar de un nivel de vida adecuado, también necesitamos una concepción de Estado que permita desarrollar éste principio de la democracia. ${ }^{37} \mathrm{Y}$ esta concepción del Estado no es otra que la noción de Estado

35 "What is essential in a modern democratic theory? As soon as democracy is seen as a kind of society, not merely a mechanism of choosing and authorizing governments, the egalitarian principle inherent in democracy requires not only 'one man, one vote' but also 'one man, one equal effective right to live as fully humanly ads he may wish'. Democracy is now seen, by those who want it and by those who have it (or are said to have it) and want more of it, as kind of society - a whole complex of relations between individuals- rather than simply a system of government. MACPHERSON C.B. Democratic Theory: Essays in Retrieval. Oxford Clarendon Press, 1973, p. 51.

36 MACPHERSON C.B La Democracia Liberal y su Época. Alianza Editorial, 1997, pp. 137- 138.

37 Cfr. MACPHERSON, CB. ¿Necesitamos una teoría del estado? En MACPHERSON CB. Ascenso y Caida de la Justicia económica y otros ensayos. El papel del estado, las clases y la propiedad en la democracia del siglo XX Oxford University Press (1985) pp.75-99. En este ensayo, Macpherson se pregunta si en el mundo de hoy es necesaria una teoría del Estado, o bien este ha sido superado por el progreso y avance de la sociedad capitalista, en la cual las estructuras dependen cada vez más de actores privados. Macpherson concluye que, debido a las enormes desigualdades que el sistema produce, la teoría liberal del Estado tiene que tomar elementos propios del socia- 
Constitucional, Social y Democrático de Derecho.

El Estado Consitucional, Social y Democrático de Derecho es el producto de una larga evolución histórica que refleja distintos momentos en la evolución del constitucionalismo. En un primer momento, surge la noción de "Estado de Derecho" que es aquella que tiene como propósito proteger la libertad de la persona por medio de la sujeción de la actividad del Estado al Derecho, con el propósito que sus actividades no infringieran las libertades de los ciudadanos, siendo su principal manifestación el principio de legalidad para legitimar la actuación de los órganos de la administración, en cuanto "cara visible" del Estado frente a los ciudadanos. ${ }^{38}$

Posteriormente surge la noción de Estado Social, que surge como respuesta a los excesos del liberalismo producidos por el modelo económico capitalista, que produjo graves desigualdades, cuya satisfacción comenzó a ser solicitada por las personas, en el entendido que son acreedoras del Estado en cuanto legitimadotas del mismo. De esta forma, el Estado Social es un Estado que persigue la realización de una idea de igualdad a partir de la asignación estatal de mínimos materiales a favor de grupos sociales, ${ }^{39}$ que se manifiestan en determinadas prestaciones. Por otra parte, este modelo de Estado Social se complementa con el hecho de que la legitimación del mismo viene dado por la democracia, que es el sistema a través del cual la ciudadanía elige a las autoridades que vendrán a desarrollar las obligaciones del Estado para con las personas.

El diseño conceptual se completa con la noción de "Estado Constitucional" que es aquel que reconoce a la Constitución como límite y fundamento de su poder, y que establece derechos fundamentales que son la principal garantía para los ciudadanos y el principal título para encauzar toda la actividad del Estado ${ }^{40}$.

A partir de esta idea de Estado, que se encuentra obligado constitucionalmente a satisfacer derechos sociales, podemos señalar que, dentro de las funciones del mismo, el principal título de intervención para dicha actividad, a nuestro juicio compete a la Administración. Más arriba señalamos que el concepto de derechos sociales no puede ser cuestionado en aras de una supuesta legitimidad democrática, pues bien, en este sentido estamos de acuerdo con Forsthoff que existe una preferencia hacia la Administración respecto a la satisfacción de estos derechos, puesto que es la que está más en contacto con las necesidades concretas que exigen su satisfacción, señala al respecto "La Administración se enfrenta con la realidad social del modo más directo

lismo para enriquecer y fortalecer sus estructuras y fines con el propósito de contener y ser una alternativa para los ciudadanos al momento de resguardar sus derechos. De esta forma, hoy también aparece como necesario preguntarse si necesitamos una nueva teoría del Estado.

38 COSSIO, J. R. Estado Social y Derechos de Prestación, Centro de Estudios Constitucionales, 1989, pp. 27-28.

COSSIO, J. R. Op. cit. pp. 32-33.

40 El desarrollo conceptual del Estado Constitucional, Social y Democrático de Derecho es el proceso de formalización de las actividades estatales, al respecto seńala Cossio "Al desarrollarse el Estado social (y el valor de la igualdad) a partir de algunos postulados formales del Estado de Derecho, cabe hablar de una nueva materialidad de éste último y de la juridificación de las ideas sociales planteadas, hasta hace no mucho, fuera de la Constitución. COSSIO, J. R. Op. cit. p. 37. 
y no puede esquivar sus exigencias. Casi todas las instituciones de nuestro Derecho público, que han transformado al Estado en un Estado social, son obra de la legislación y de la administración” ${ }^{\prime 1}$.

Esta afirmación de deferencia hacia la administración se ve reflejada en nuestro sistema de protección de los derechos sociales en la implementación del sistema Chile Solidario, que en sus orígenes fue de implementación administrativa ${ }^{42}$. Por otra parte, el núcleo mismo de la actividad administrativa, la noción de servicio público, da cuenta de esta preferencia a la administración, al pasarse de un estado benefactor a un estado garantizador de derechos. ${ }^{43}$ Este modelo de estado garantizador de derechos, que supone un aumento y modificación de sus fines tradicionales, requiere la necesidad de sofisticar sus funciones. El viejo y rígido esquema de la separación de poderes no es compatible con un Estado que tiene que desarrollar un sin fin de actividades diversas. Esta diversificación de actividades es más factible de ser desarrollada a través de la Administración ${ }^{44}$, que cuenta con instrumentos flexibles y eficaces para enfrentar las necesidades "Es por medio del aparato administrativo como adquieren relevancia las políticas articuladas en la Constitución" ${ }^{\prime 5}$ y en particular, respecto de los derechos sociales, se concretiza mediante las actividades de prestación, puesto que, tal como señala Huerta "La función de prestación se encuentra asignada al brazo activo del gobierno que es la administración pública, aún cuando el origen de las prestaciones se encuentre en derechos fundamentales [sociales] que se encuentran referidos todos los órganos del Estado para su protección y garantía." ${ }^{46}$

Sin perjuicio de la eficiencia que la literatura reciente reconoce a la Administración, no es menos cierto que al Legislador le corresponde el rol de establecer políticas permanentes en el tiempo, por una parte y por otra, desarrollar vía legislativa el contenido de los derechos sociales. En el caso chileno, la preferencia a la administración en materia de derechos sociales no es solo un imperativo de carácter técnico, sino que encuentra consagración constitucional en los artículos $24^{47}$ y $65^{48}$ de la Constitución,

${ }^{41}$ FORSTHOFF, E. Concepto y esencia del Estado social de derecho en ABENDROTH, W.; FORSTHOFF E.; DOHERING, K. El Estado Social, Centro de Estudios Constitucionales, 1996, p. 78.

42 Hacer nota al estudio de implementación del sistema Chile Solidario.

43 Al respecto Alex Valladares, en un interesante trabajo seńala que el cambio de paradigma desde la noción de "servicialidad" de la administración hacia un estado que garantiza mínimos "requiere de una intervención más intensa y directa en aras de la consecución y construcción de técnicas jurídicas que garanticen el bienestar general de los ciudadanos; en otras palabras que haga posible el libre desarrollo de ellos y el pleno ejercicio de los derechos fundamentales por todos. El Estado ya no es, en consecuencia un mero prestador de servicios; el Estado es ante todo garantizador de derechos y libertades ciudadanas". VALLADARES, A. Sobre el Gatopadismo del Servicio Público s/f. P. 34 .

44 HUERTA, C. La intervención administrativa en el Estado Contemporáneo en CIENFUEGOS, D. y LÓPEZ OLVERA, A. (coords.) Estudias en homenaje a don Jorge Fernández Ruiz. Tomo I, Derecho Administrativo. Instituto de Investigaciones jurídicas UNAM, 2005, p. 124.

45 Ibíd.

46 HUERTA, C. Op. cit., p. 129

47 Señala dicho artículo en su inciso primero, "El gobierno y la administración del Estado corresponden al Presidente de la República, quien es el Jefe del Estado"

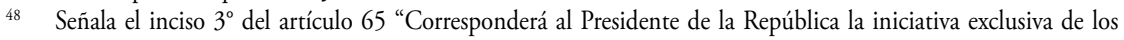


que consagran un modelo presidencialista ${ }^{49}$ en el cual al Presidente de la República, y por ańadidura a la Administración, le corresponde el gobierno y la iniciativa exclusiva de ley en aquellos aspectos proyectos que impliquen gastos y, específicamente, la elaboración del presupuesto de la nación, que es el instrumento clave para impulsar cualquier tipo de política social que desarrollo los derechos sociales.

Sin ánimo de entrar en detalle en la discusión sobre el carácter más o menos democrático del modelo presidencialista ${ }^{50}$, en lo que nos interesa, que es las formas en que el Estado cumple su obligación de garantizar los derechos sociales, nos parece que las excesivas facultades del presidente de la república en materia de derechos sociales deja afuera las iniciativas que pudieran tener los representantes de la ciudadanía en el Congreso respecto de los derechos sociales, relegando los Senadores y Diputados a un rol secundario que solo puede consistir en disminuir o rechazar los gastos propuestos por el Ejecutivo, pero en ningún caso poder generar iniciativas propias, lo que a mi juicio constituye, al final del día, un déficit de nuestro sistema, pues dependemos de una autoridad (el presidente) comprometida con la causa de los derechos sociales para tener iniciativas legislativas - y por cierto administrativas- para la garantía de los derechos sociales; En el evento que una autoridad de corte neoliberal tenga el control del poder, probablemente la garantía de estos derechos se vería profundamente deprimida, como sucedió durante la dictadura de Pinochet, hecho al cual me he referido anteriormente en este trabajo. ${ }^{51}$

\section{Un caso de satisfacción de derechos sociales y estrategia política: Chile Solidario y la coordinación a favor de las capacidades}

Tal como hemos dicho más arriba, en el modelo chileno existe una preferencia hacia la administración para el cumplimiento de las obligaciones que emanan de los derechos sociales. En esta sección nos referiremos a un programa que el Estado de Chile ha desarrollado para enfrentar de manera integral un área relacionada con los derechos sociales, la superación de la extrema pobreza.

La cobertura constitucional de esta intervención estatal, la encontramos en el artículo $1^{\circ}$ de la Constitución que dispone que "Las personas nacen libres e iguales en dignidad y derechos", "La familia es el núcleo fundamental de la sociedad", "El Estado está al

proyectos de ley que tengan relación con la alteración de la división política o administrativa del país, o con la administración financiera o presupuestaria del Estado"

49 Modelo con un Ejecutivo altamente organizado.

50 Un autor que ha sido particularmente crítico del modelo presidencialista es Pablo Ruiz-Tagle, quien señala que nuestra Constitución, en realidad consagra un modelo de Neopresidencialismo, que se caracteriza por una desigualdad que se extiende por todo el modelo, desde el desbalance entre las atribuciones del ejecutivo y el legislativo hasta las normas de derechos fundamentales, que establecen de manera muy tenue los derechos sociales. RUIZ-TAGLE, P. "La Trampa del neopresidencialismo: la Constitución Gatopardo” en Op. cit. p. 203.

51 Vid. Supra nota 8. 
servicio de la persona humana y su finalidad es promover el bien común, para lo cual debe contribuir a crear las condiciones sociales que permitan a todos y a cada uno de los integrantes de la comunidad nacional su mayor realización espiritual y material posible, con pleno respeto a los derechos y garantías que esta Constitución establece” y "Es deber del Estado (...) dar protección a la población y a la familia, propender al fortalecimiento de ésta, promover la integración armónica de todos los sectores de la Nación y asegurar el derecho de las personas a participar con igualdad de oportunidades en la vida nacional."

Como podemos apreciar, esta disposición es bastante compleja, pues establece derechos sociales y obligaciones concretas para el Estado en distintos niveles. El sistema Chile Solidario cubre estas obligaciones, también mediante un complejo sistema donde interactúan tanto distintos órganos constitucionales, el ejecutivo y el legislativo, diversos instrumentos, subsidios directos, regulaciones preferentes, apoyos profesionales, siendo el sujeto beneficiado por el sistema no una persona determinada, sino un núcleo familiar.

El Ministerio de Planificación, que es la agencia pública encargada de llevar adelante los programas de superación de pobreza define el plan Chile Solidario como un Sistema de Protección Social que tiene como propósito ayudar a que 225.073 familias chilenas salgan de la extrema pobreza en que viven, a través de la ejecución de planes con una perspectiva integradota, que combina la asistencia (mediante transferencias directas de recursos) y la promoción (acompańamiento profesional y compromisos de cumplimiento de determinados niveles mínimos en salud, educación).

El sistema Chile Solidario es el mejor ejemplo de la tesis que he defendido en este trabajo, respecto al equilibrio precario que sustenta la garantía de los derechos fundamentales, puesto que en su desarrollo, este sistema apela a la coordinación de los órganos que brindan prestaciones sociales, con el propósito que los recursos fiscales que ya están destinados al área social, sean mejor aprovechados contribuyendo a intensificar la focalización de los mismos.

El Sistema Chile Solidario se concibe como una estrategia de acción integral orientada a la oferta intencionada de servicios y beneficios a las personas y familias más pobres, que contempla mecanismos precisos de focalización, con el propósito de llegar a las personas que efectivamente necesitaran salir de la extrema pobreza. Para ello, el sistema se centra en la familia como "unidad de intervención" en torno a la cual se desarrolla una estrategia de apoyo que permita generar y fortalecer capacidades con el propósito que una vez que se sale de la pobreza, no se vuelva a ingresar. ${ }^{52}$

Cuando surge la voluntad política y el compromiso de la autoridad respecto a la necesidad de abordar el tema de la superación de la extrema pobreza, se hizo un diagnóstico de lo que habían sido los planes de superación de pobreza enfocados directamente en las personas, se llega a la conclusión que muchos de los factores que incidían en

52 RUIZ-TAGLE, P. Derechos fundamentales, democracia y pobreza en Op. cit. p. 312. 
la situación de extrema pobreza, decían relación con una inadecuada utilización de los recursos y servicios que el Estado ponía a disposición de las personas en forma de prestaciones, tales como educación, salud, vivienda, etc ${ }^{53}$.

De esta forma, y como una estrategia para no entrabar la implementación del plan por motivos presupuestarios, se puso énfasis en asesorar y acompañar a las familias para que accedan formal y preferencialemte a los servicios brindados por el Estado, para ello se diseńó un complejo sistema de coordinación ${ }^{54}$ de agencias públicas: Ministerios ${ }^{55}$, Servicios públicos, Municipalidades, con el propósito de lograr un mejor resultado de los programas sociales públicos.

El Sistema Chile Solidario es de vital importancia en la protección de los derechos sociales en Chile, porque abarca prácticamente todas las áreas propias de los derechos sociales, salud, educación, vivienda, alimentación, etc., a través de una lógica de fortalecimiento de capacidades en dichas áreas, más que proveyendo asignaciones directas. Este tipo de intervenciones estatales integrales han sido denominadas como intervenciones basadas en una "estrategia de derechos", que implica reunir y expresar el conjunto de objetivos, normas y sistemas por medio de los cuales la sociedad se compromete a garantizar capacidades y oportunidades para que las personas incrementen su bienestar, cuenten con mayor libertad e influyan en las decisiones que les afectan. ${ }^{56}$

Para lograr el fin perseguido por el sistema, la administración utiliza una modalidad de intervención bastante sui generis, que consiste en la celebración de un contrato o convenio que suscriben el Estado y las familias de extrema pobreza en virtud del cual, las familias se comprometen a cumplir determinadas metas de escolaridad para sus hijos, llevar a los niños y ancianos a controles periódicos de salud, que el jefe de familia acepte las ofertas de trabajo que reciba durante la vigencia del contrato, etc. ${ }^{57}$

RUIZ-TAGLE, P. Derechos fundamentales, democracia y pobreza en Op. cit. pp. 311-312.

4 La idea de la coordinación de agencias públicas, en gran medida, responde al esfuerzo desarrollado por la Dirección de Presupuestos del Ministerio de Hacienda, y en especial del director de presupuestos al que le correspondió llevar adelante el proceso de diseńo e implementación del sistema, Mario Marcel, quien ha seńalado, respecto al concepto de Estado de Bienestar que: "(...) el concepto de régimen de bienestar es más amplio que el de Estado de bienestar, porque enfatiza la racionalidad implícita de las configuraciones institucionales en contraste con la noción de políicas sociales” MARCEL, M. Del Estado de bienestar a la protección social: Reflexiones sobre regímenes de bienestar relevantes para América Latina. Conferencia brindada en el marco del seminario "Acerca del Estado de Bienestar" organizado por el Instituto Igualdad, en Marzo de 2007. En concreto, Marcel seńala que para enfrentar las contingencias propias de la protección social se requiere de la gestión de sistemas multipilares, es decir, que se apoyen en diversos agentes con el propósito de combatir de manera eficiente un fenómeno multidimensional como es la pobreza, de esta forma, el énfasis se pone en cubrir la mayor cantidad posible de áreas que inciden en la pobreza, más que centrarse en la entrega de beneficios financieros directos, cuya incidencia en la solución del problema es discutible. En resumidas cuentas, sigue el modelo de Sen en el sentido de enfocarse en las capacidades más que en las necesidades

55 Intervienen en el programa Chile Solidario Mideplan, Fosis, la Dirección de Presupuestos, las Serplac y las reparticiones regionales de los ministerios de salud, vivienda, educación, justicia, servicio nacional de la mujer, entre otros. RUZ, M., y PALMA, J. Análisis del proceso de elaboración e implementación del Sistema Chile Solidario (Informe premilitar) Instituto de Asuntos Públicos, Universidad de Chile, 2005, p.46.

56 RUIZ-TAGLE, P. Derechos fundamentales, democracia y pobreza en Op. cit. p. 312.

57 Para un detalle del plan Chile Solidario ver, MIDEPLAN. Conceptos Fundamentales Sistema de protección Chile Solidario Diciembre de 2004. 


\section{A modo de conclusión, corolario del equilibrio precario: un contrato como método de intervención directa de la administración en materia de derechos sociales}

A modo de conclusión, cabe señalar que a lo largo de este trabajo se ha defendido la tesis que gracias al equilibrio precario que supone la satisfacción de los derechos sociales, podemos entender que la necesidad de reconocer las obligaciones del Estado para su garantía.

Un corolario que da cuenta de esta precariedad, pero que a la vez demuestra la efectividad de esta condición es el Sistema Chile Solidario, el que, a pesar de los complejos entramados jurídicos y administrativos para brindar protección social, en resumidas cuentas se valida por medio de un contrato, es decir, por uno de los símbolos de los intercambios del derecho privado.

Es posible preguntarse ¿̨de qué da cuenta el hecho de materializar mediante un contrato la vinculación al programa Chile Solidario? Y podemos responder al respecto, que da cuenta de al menos dos circunstancias claves que se vinculan con el mejor modelo de republicanismo. Por una parte, el vincular al Estado y sus ciudadanos mediante un contrato demuestra que aquél asume casi visceralmente el compromiso (y obligación) que le cabe respecto al aseguramiento de los derechos sociales, más allá de las presiones neoliberales que, en nuestro país han tejido complejas trabas constitucionales ${ }^{58}$ para, precisamente no garantizar estos derechos.

Por otra parte, apela al mejor sentido y virtud republicana, el compromiso público, puesto que la familia que firma el convenio, asume el compromiso con todos los miembros de la comunidad política, de salir de la extrema pobreza, aprovechar los espacios públicos que el Estado pone a disposición, y, lo que es más importante, asume un compromiso colectivo para lograr tal propósito.

58 Basta tener en cuenta las limitaciones constitucionales establecidas en el artículo 20 respecto a la posibilidad de interponer recursos de protección respecto al derecho a la educación, derecho a la salud, derecho a la seguridad social, entre otras restricciones. 